\title{
Thermal Plasma Analysis for the Pyrolysis of PFCs on a Large Scale
}

\author{
Sooseok Choi, Hyun Seok LeE, Sungwoo KIM and Sang Hee HonG* \\ Department of Nuclear Engineering, Seoul National University, Seoul 151-742 \\ Dong-Wha PARK \\ Department of Chemical Engineering, Inha University, Inchon 402-751
}

(Received 2 September 2008, in final form 13 February 2009)

\begin{abstract}
The effects of the arc current and the gas flow rate in a plasma torch on the thermal plasma decomposition process have been analyzed to improve its economic feasibility for the pyrolysis of perfluorocompounds (PFCs). A 200-slpm waste gas mixture of $1 \% \mathrm{CF}_{4}$ and $99 \% \mathrm{~N}_{2}$ purging gas was decomposed by using a nitrogen thermal plasma generated by using a plasma torch with hollow electrodes. A thermal efficiency of over $50 \%$ was achievable with a torch input power of $40 \mathrm{~kW}$ operated at $150 \mathrm{~A}$ and $70 \mathrm{slpm}$ as a result of a stable attachment of the cathodic arc root near the plasma gas injection area. Measurements in the thermal plasma pyrolysis showed a more than $96 \%$ destruction and removal efficiency (DRE) of $\mathrm{CF}_{4}$, which turned out to be mainly affected by the net plasma thermal power, which depended on the thermal efficiency of the torch, regardless of the input electric power. The plasma torch operated with a higher gas flow rate showed an increased $\mathrm{CF}_{4}$ DRE by enhancing the turbulent mixing effects of the thermal plasma jet having a relatively higher axial velocity with a steep gradient from the reactor entrance. However, a higher flow-rate gas disturbs the cathodic arc attachment around the gas injection area, which causes a considerably increased electric power consumption. Plasma torch operation at a low gas flow rate and high current is expected to be effective in increasing its thermal efficiency with a sufficiently high DRE for industrial application of thermal plasma pyrolysis to the treatment of PFCs due to its low running cost for electric power and working gas.

PACS numbers: 52.75.Hn, 52.77.Fv, 52.77.-j, 52.80.Mg

Keywords: Plasma torch with hollow electrodes, PFC decomposition, Thermal efficiency, Thermal plasma characteristics, turbulent mixing

DOI: $10.3938 /$ jkps.55.1819
\end{abstract}

\section{INTRODUCTION}

It is well known that perfluorocompounds (PFCs) are considered as serious greenhouse gases [1,2], and international efforts like the Kyoto Protocol and Bali Roadmap have been made for reducing such global warming materials. However, along with rapid growth of the semiconductor and display industry, the exhaust of PFCs used in plasma etching and cleaning processes has increased more and more every year. Therefore, practical research on large-scale treatment of flue gases, including PFCs, is urgently required for continuous prosperity.

Although the conventional combustion method by using a natural gas burner, combined with a wet scrubber, is widely used to treat waste gas [3], it has an insufficient flame temperature to achieve high destruction and removal efficiency (DRE) of $\mathrm{CF}_{4}$, which is the most stable species among the PFCs [4]. Besides low DRE,

*E-mail: hongsh@snu.ac.kr;

Fax: +82-2-889-2688 the combustion process has the side effect of generating large quantities of $\mathrm{CO}_{2}$ and $\mathrm{NOx}$. In order to overcome these disadvantages in the combustion process, a variety of other methods, such as a dielectric barrier discharge [5] combined with chemical catalyst [6], a microwave discharge [7], and a low-pressure inductively coupled plasma [8], has been introduced. Although these methods have been reported to destruct PFCs effectively at low temperatures with high DRE, they have shown a limited treatment capacity of less than 1 slpm until now [9]. Although Hartz et al. decomposed 10.6 slpm of waste gases with a high DRE of $99.6 \%$, the waste gases consisted mostly of reactive natural gas and oxygen [10].

On the other hand, large-scale pyrolysis based on thermal plasma decomposition at high temperatures of several thousand degrees is available, together with its high DREs of PFCs [11]. In addition, generation of unwanted byproducts, such as $\mathrm{CO}_{2}, \mathrm{COF}_{2}, \mathrm{NO}_{x}$ and so on, are effectively prevented in the thermal plasma pyrolysis process [12] because any kind of gas can be used as a working gas. However, the thermal plasma has the demerits 


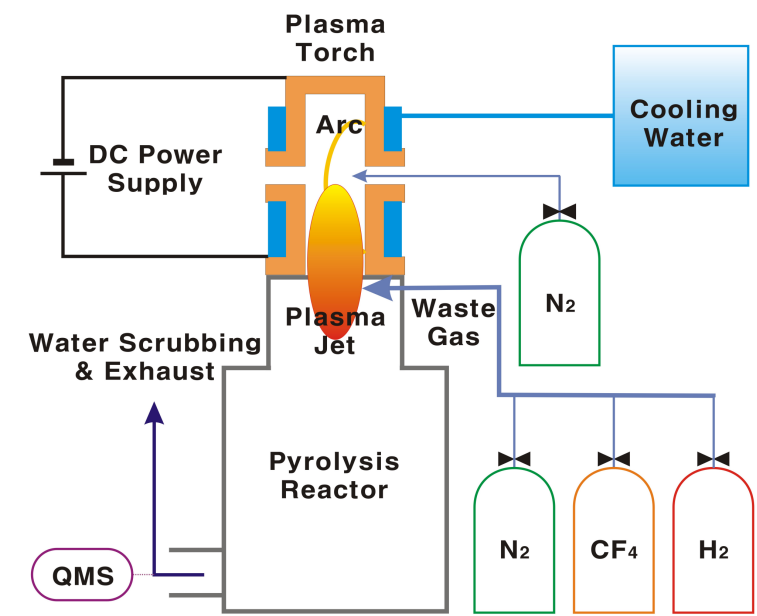

Fig. 1. Schematic diagram of an experimental setup for the thermal plasma decomposition of $\mathrm{CF}_{4}$.

of large consumptions of electric input power and of a plasma forming gas in the case of commercializing its process. For this reason, the effects of the arc current and the gas flow rate supplied to the plasma torch on the thermal decomposition of $\mathrm{CF}_{4}$ have been experimentally illustrated and numerically analyzed in order to improve the economic feasibility of the thermal plasma process for PFC pyrolysis.

\section{EXPERIMENTAL SETUP AND NUMERICAL MODELING}

A schematic diagram of the experimental setup is presented in Figure 1. The high temperature of thermal plasma jet is generated by a dc plasma torch with hollow electrodes [13] to decompose a waste gas. In order to investigate the effects of the torch operation conditions on the thermal plasma decomposition process, we supplied arc currents of $130 \sim 150 \mathrm{~A}$ and plasma gas flow rates of $70 \sim 90 \mathrm{slpm}$ to the torch. The thermal efficiency of the torch, defined as the fraction of input power transferred to the thermal plasma, was obtained from measurements of the temperature rise and the coolant flow rate in every operating condition. Since $\mathrm{CF}_{4}$ gas is the most non-degradable compound among various PFCs, a mixture of $1 \% \mathrm{CF}_{4}$ and $99 \% \mathrm{~N}_{2}$ purging gas was used as a waste gas. In this experimental work, the total flow rate of the waste gas was set as $200 \mathrm{slpm}$, so that the $\mathrm{CF}_{4}$ flow rate was 2 slpm. A hydrogen $\left(\mathrm{H}_{2}\right)$ additive of $4 \mathrm{slpm}$ was mixed with the waste gas containing 2 -slpm $\mathrm{CF}_{4}$ as a reactant gas to increase the treatment efficiency induced by the following chemical reaction $[11,12]$ :

$$
\mathrm{CF}_{4}+2 \mathrm{H}_{2} \rightarrow \mathrm{C}(\mathrm{g})+4 \mathrm{HF}
$$

where the gas phase carbon $\mathrm{C}(\mathrm{g})$ is sublimated into a solid state carbon at the reactor wall, and $\mathrm{HF}$ is eas-

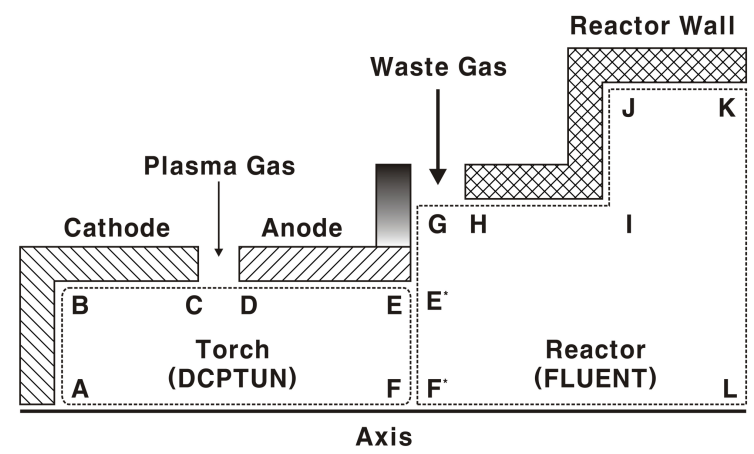

Fig. 2. Computational domains and numerical codes (DCPTUN and FLUENT) used for the torch interior and reactor inside modeling, respectively.

ily dissolved in water. The waste gas mixture is introduced into the pyrolysis reactor perpendicular to the flame ejecting direction at the exit of the plasma torch. The decomposed and generated gases inside the reactor are scrubbed by water and are exhausted to the atmosphere. In order to measure the gas composition and the DRE of $\mathrm{CF}_{4}$, we extracted some treated gases and analyzed them by using a quadrupole mass spectrometry (QMS) system before the exhaust $[12,14]$.

Numerical analyses on the thermal plasma jet mixed with the waste gas were carried out to examine the effects of the torch operation conditions on the $\mathrm{CF}_{4}$ decomposition. The simulation was divided into two steps, as shown in Figure 2. Firstly, the thermal plasma characteristics in the torch region were numerically analyzed by using the DCPTUN code developed in the authors' laboratory [15-17]. Secondly, the turbulent flow characteristics inside the reactor region were predicted by using the commercial FLENT code. The temperature and the velocity profiles at the torch exit $(\mathbf{E F})$ calculated in the first step, were used as the reactor inlet boundary $\left(\mathbf{E}^{\star} \mathbf{F}^{\star}\right)$ conditions in the second step. For all numerical simulations, the governing equations, consisting of mass, momentum, and energy conservation, were solved under the steady-state, two-dimensional, and axisymmetric assumptions. The standard $K-\varepsilon$ model was employed to include the turbulent flow characteristics of thermal plasma and to analyze the turbulent mixing effect between the plasma flame and the waste gas.

\section{RESULTS AND DISCUSSION}

Experimental results for the arc voltage, input power, thermal efficiency, net power, and DRE of $\mathrm{CF}_{4}$ are listed in Table 1 according to the torch operating conditions. The net powers of the thermal plasma jet, $\mathbf{P}_{\text {net,exp }}$, are obtained by subtracting the coolant heat loss from the electric input power supplied to the torch; i.e., $\mathbf{P}_{\mathbf{n e t}, \mathbf{e x p}}$ is the real power deposited on the waste gas. Since the 
Table 1. Operating conditions of the torch used in the pyrolysis process, and the corresponding arc voltage, input power, thermal efficiency, net power obtained by experiment, $\mathrm{DRE}$ of $\mathrm{CF}_{4}$, and net power ratio between numerical and experimental results.

\begin{tabular}{cc|cccc|cc}
\hline \hline $\boldsymbol{I}(\mathrm{A})$ & $\boldsymbol{Q}(\mathrm{slpm})$ & $\boldsymbol{U}(\mathrm{V})$ & $\boldsymbol{P}_{\text {in }}(\mathrm{kW})$ & $\eta(\%)$ & $\boldsymbol{P}_{\text {net,exp }}(\mathrm{kW})$ & $\boldsymbol{D R \boldsymbol { E } ( \% )}$ & $\boldsymbol{P}_{\text {net }, \text { num }} / \boldsymbol{P}_{\text {net }, \text { exp }}$ \\
\hline 130 & 70 & 397.4 & 51.7 & 42.7 & 22.1 & 97.4 & 0.959 \\
130 & 90 & 392.9 & 51.1 & 43.3 & 22.1 & 99.5 & - \\
140 & 70 & \multicolumn{7}{c}{ Unstable arc voltage } \\
140 & 90 & 406.3 & 56.9 & 40.4 & 23.0 & 98.5 & 1.041 \\
150 & 70 & 264.3 & 39.6 & 51.8 & 20.6 & 96.9 & 0.946 \\
150 & 90 & 398.1 & 59.7 & 41.8 & 25.0 & 99.4 & 0.976 \\
\hline \hline
\end{tabular}

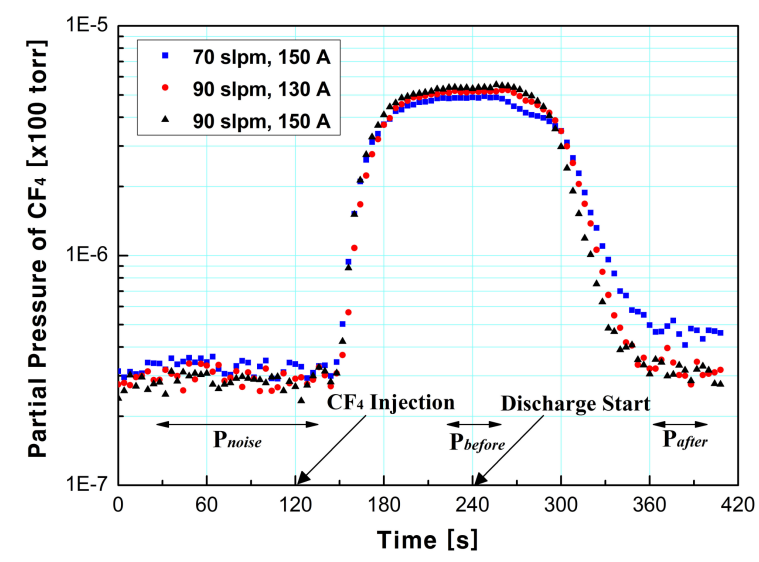

Fig. 3. Evolution of the partial pressures of $\mathrm{CF}_{4}$ measured during the pyrolysis process according to the torch's operation conditions.

net power indicates a sufficiently high level from 20.6 to $25.0 \mathrm{~kW}$ under all operating conditions, high DREs of $\mathrm{CF}_{4}$ of over $96 \%$ are measured without reference to the electric input power, which varied from 39.6 to $59.7 \mathrm{~kW}$. The DRE is calculated from the measured partial pressures of $\mathrm{CF}_{4}$ during the pyrolysis process, which depends on the torch operating conditions, as shown in Figure 3.

Under most operating conditions, the thermal efficiencies of the torch were measured to be about $40 \%$ in operations with electric input powers of 50 to $60 \mathrm{~kW}$ and high arc voltage of about $400 \mathrm{~V}$. However, a high thermal efficiency of $51.8 \%$ with a low input power of $39.6 \mathrm{~kW}$ and a low arc voltage of $264.3 \mathrm{~V}$ was achieved at the torch operating condition of $150 \mathrm{~A}$ and $70 \mathrm{slpm}$. Generally, the arc voltage is in proportion to the arc length between its roots on the cathode and the anode surfaces. In the hollow electrode torch, because both the cathode and the anode arc roots move back and forth on the cylindrical electrode surface, it is very difficult to find the arc root positions properly based on a reliable theoretical basis. However, the cathode spot position can be successfully predicted by using the cold flow analysis suggested by Brillhac et al. [18]. By adopting this method, the axial velocity profiles of the cold gas at a distance of $0.5 \mathrm{~mm}$ from the cathode wall are calculated without an electric arc in the case of 70- and 90-slpm gas flow rates, and in both the cases, the cathode spot position is predicted to be not far behind the vortex chamber for plasma gas injection (around $\mathbf{C}$ in Figure 2), because the gas flow rate used in this work is very small compared with one for the typical operating conditions of a hollow-electrodetype torch [13,15-18]; thus, the gas drag force acting on the cathodic arc root is too small to push the arc against its Lorentz force far away from the gas injection area.

However, traces of cathodic arc spots are experimentally observed in two separate erosion areas, around B and $\mathbf{C}$ in Figure 2, after discharges under various operating conditions. An unstable cathodic arc attachment seems to take place in the case of low current and high gas flow rate due to the low electric conductivity in a low-temperature environment. In this unstable condition for the arc discharge, even if the cathode spot is initially formed around the gas injection area, it moves toward the corner around $\mathbf{B}$ of the cathode end where the electric field is concentrated. Consequently, the cathodic arc attachment position is re-determined by the balance of the self-induced magnetic force and the drag force without disturbing the cold gas injected between $\mathbf{C}$ and $\mathbf{D}$. On the other hand, because a torch operating condition of $150 \mathrm{~A}$ and $70 \mathrm{slpm}$ is the most favorable to generate a high-temperature thermal plasma among all the operating conditions in this work [13], a stable cathodic arc root is expected to be attached at around C under this condition. Therefore, in the arc voltage fluctuation measurements, only the case of $150 \mathrm{~A}$ and 70 slpm shows a stable low arc voltage due to the shortest arc length while a sudden change in the arc voltage fluctuation is too frequently observed in the case of $140 \mathrm{~A}$ and $70 \mathrm{slpm}$. Although, plasma torches are usually operated in the restrike mode with continuous movement of the anodic arc root [19], a time-averaged anode spot position is assumed in the numerical analysis because it has described the thermal plasma characteristics correctly in a previous work $[13,15,17]$.

In order to evaluate the numerical results in the torch's inside area, the calculated net power, $\mathbf{P}_{\text {net,num, which }}$ is obtained from integration of the plasma power density over the torch exit area, is compared with the measured

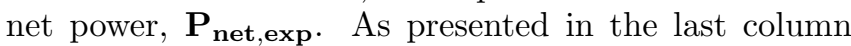




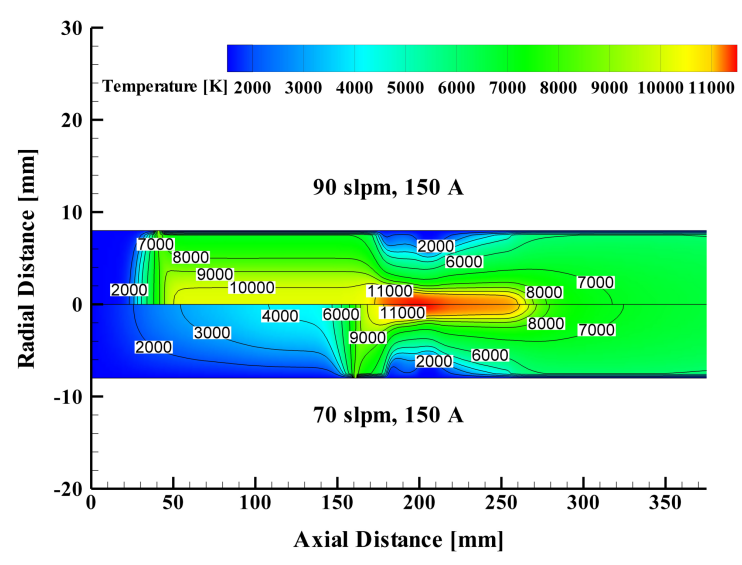

Fig. 4. Comparison of the plasma temperature distributions inside the torch for two flow rates of 70 (below) and 90 (above) slpm at the same arc current of $150 \mathrm{~A}$.

in Table 1, the numerical results are in good agreement with the experimental ones, and the differences are less than $5.4 \%$ under all operating conditions.

In Figure 4, the plasma temperature distributions inside the torch are compared for 70 and 90 slpm at the same input current of 150 A. Since a cold plasma gas is injected at the axial position between 200 and 202 $\mathrm{mm}$, a low-temperature region usually appears at around $200 \mathrm{~mm}$. Because the injected plasma forming gas is heated by the arc, a large-area high-temperature plasma is formed as a result of the arc length being considerably longer at higher flow rates. For this reason, the heat loss by conduction from a high-temperature thermal plasma to the cathode cooled by water is increased for a torch operating with a long arc, and a high thermal efficiency of $51.8 \%$ is achieved only in the case of $150 \mathrm{~A}$ and 70 slpm due to a stable cathodic arc attachment near the plasma gas injection area.

Figure 5 shows the calculated radial distributions of the plasma temperature and the velocity on the torch exit plane for various torch operating conditions. At the center of the thermal plasma jet, the differences in temperature and velocity between their maximum and minimum values, which depend on the torch operating conditions, are calculated as $4.04 \%$ and $19.92 \%$, respectively. The velocity profiles are divided into two groups according to gas flow rate, as seen in Figure 5(b). In the case of high flow rate, relatively high DREs of $\mathrm{CF}_{4}$ are measured compared with low-flow conditions, as shown in the Table 1. Because all the temperature profiles plotted in Figure 5(a) are similar in their distributions and are sufficiently high enough for decomposing $\mathrm{CF}_{4}$, the different velocity profiles for different plasma gas flow rates affect the mixing of the waste gas with the thermal plasma jet.

In order to examine the effects of the plasma gas flow rate on the $\mathrm{CF}_{4}$ pyrolysis process, we compare contour plots of the plasma temperature and the $\mathrm{CF}_{4}$ mole fraction inside the reactor in Figure 6 for the two flow cases
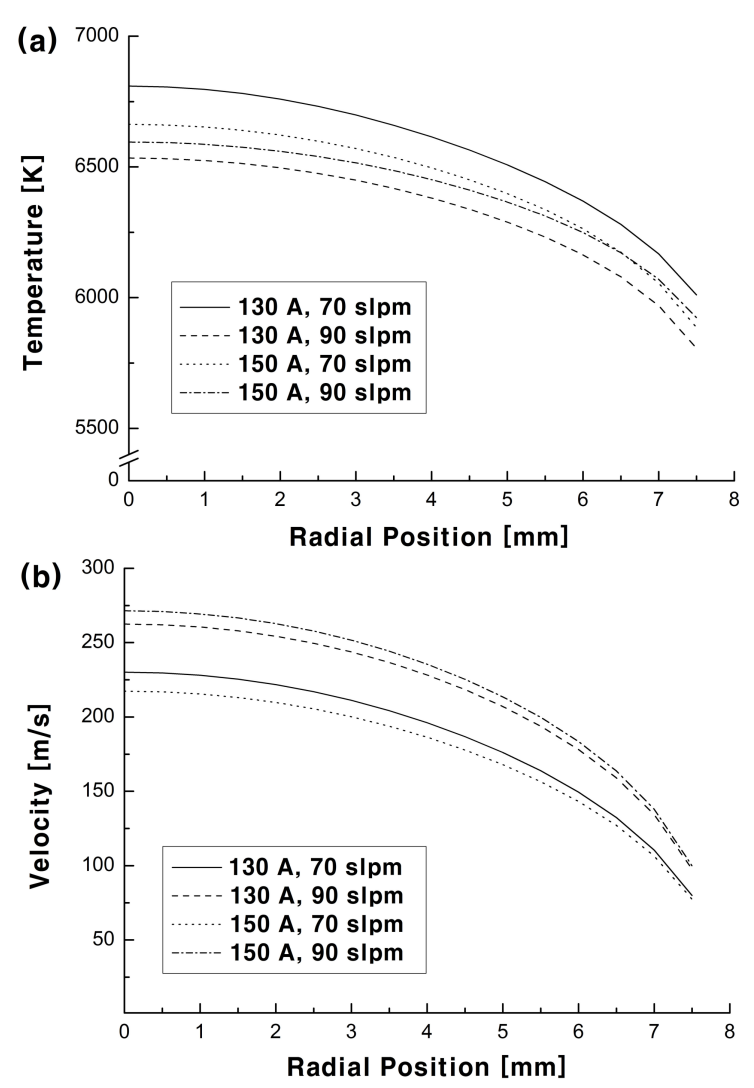

Fig. 5. Radial profiles of (a) the temperature and (b) the velocity of a thermal plasma jet at the torch exit for various torch operation conditions.

of 70 and 90 slpm for the same arc current of $150 \mathrm{~A}$. In the low-flow case, a low-temperature region, under $1000 \mathrm{~K}$, caused by the cold waste gas introduced into the reactor is expanded along the reactor wall surface, and a relatively high concentration of $\mathrm{CF}_{4}$ appears in this region compared with high-flow case. Because of this high $\mathrm{CF}_{4}$ concentration in a low-temperature environment, the DRE of $\mathrm{CF}_{4}$ in the case of $70 \mathrm{slpm}$ is lower than that in the case of $90 \mathrm{slpm}$.

Although a high gas flow rate produces a high axial velocity of the thermal plasma jet at the torch exit, rapidly slowing velocities are predicted inside the reactor region, as shown in Figure 7(a). As illustrated in Figure 7(b), the turbulence intensity of the high-flow case is stronger than that for the low-flow case, especially at the axial position around $400 \mathrm{~mm}$ where the waste gas begins to be mixed with the thermal plasma jet. Because the steep gradient of the velocity in the peripheral region of the thermal plasma jet causes entrainment of ambient gas into the plasma $[14,20]$, an enhanced gas mixing between the thermal plasma jet and the waste gas with a strong turbulent intensity, is expected under the high flow rate condition. 
(a)

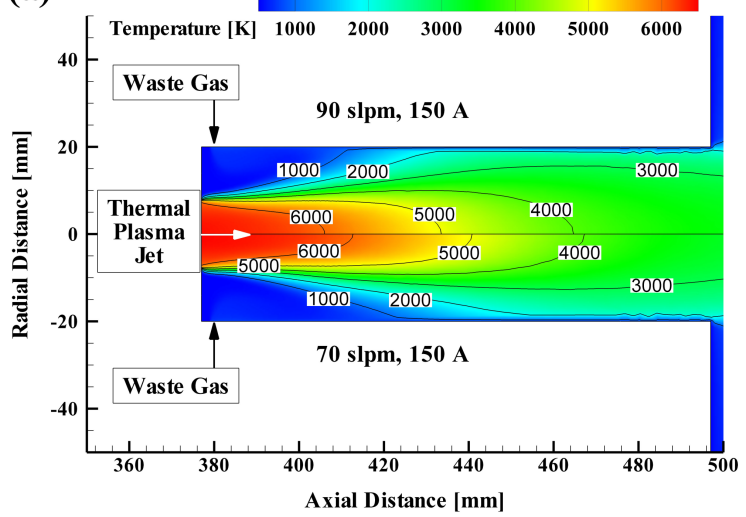

(b)

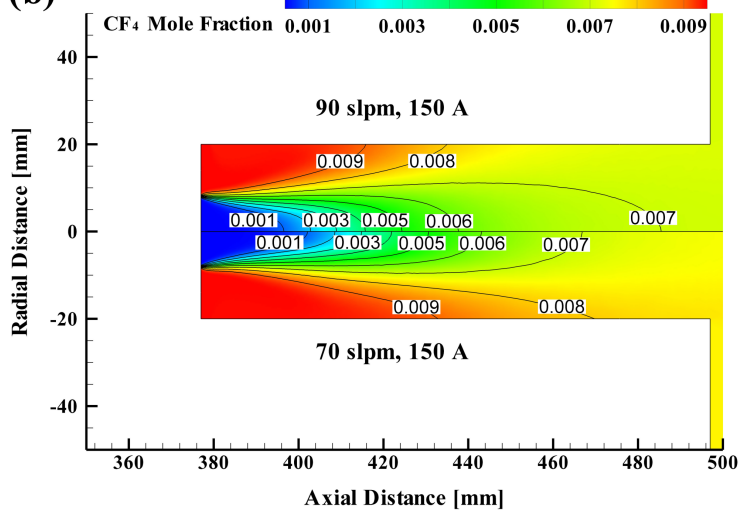

Fig. 6. Contour plots of (a) the plasma temperature and (b) the $\mathrm{CF}_{4}$ mole fraction inside the reactor region for the flow rates of 70 (below) and 90 (above) slpm at the same arc current of $150 \mathrm{~A}$.

\section{CONCLUSION}

The numerical and the experimental results for the thermal plasma pyrolysis process revealed that a plasma torch operated with a higher flow rate of the plasma forming gas is more proper to increase the $\mathrm{CF}_{4} \mathrm{DRE}$ by enhancing turbulent mixing effects of the thermal plasma jet having a relatively higher axial velocity with a steep gradient from the reactor entrance. The $\mathrm{CF}_{4} \mathrm{DRE}$ turns out to be mainly affected by the net plasma thermal power, which depends on the thermal efficiency of the torch and the input electric power. However, a higher flow rate of the cold plasma forming gas disturbs the cathodic arc attachment around the gas injection area, which causes a considerably increased electric power consumption. In the case of $150 \mathrm{~A}$ and $70 \mathrm{slpm}$, by taking advantage of a stable cathodic arc attachment near the plasma gas injection area, $22.2 \%$ of the plasma gas and $33.7 \%$ of electric power are saved at the cost of a $2.5 \%$ reduction in the $\mathrm{CF}_{4} \mathrm{DRE}$, compared with the case of $150 \mathrm{~A}$ and 90 slpm. Therefore, a plasma torch operation with a low plasma gas flow rate will be preferable to one with a high flow rate at the same current to increase its thermal efficiency with a sufficiently high DRE for the
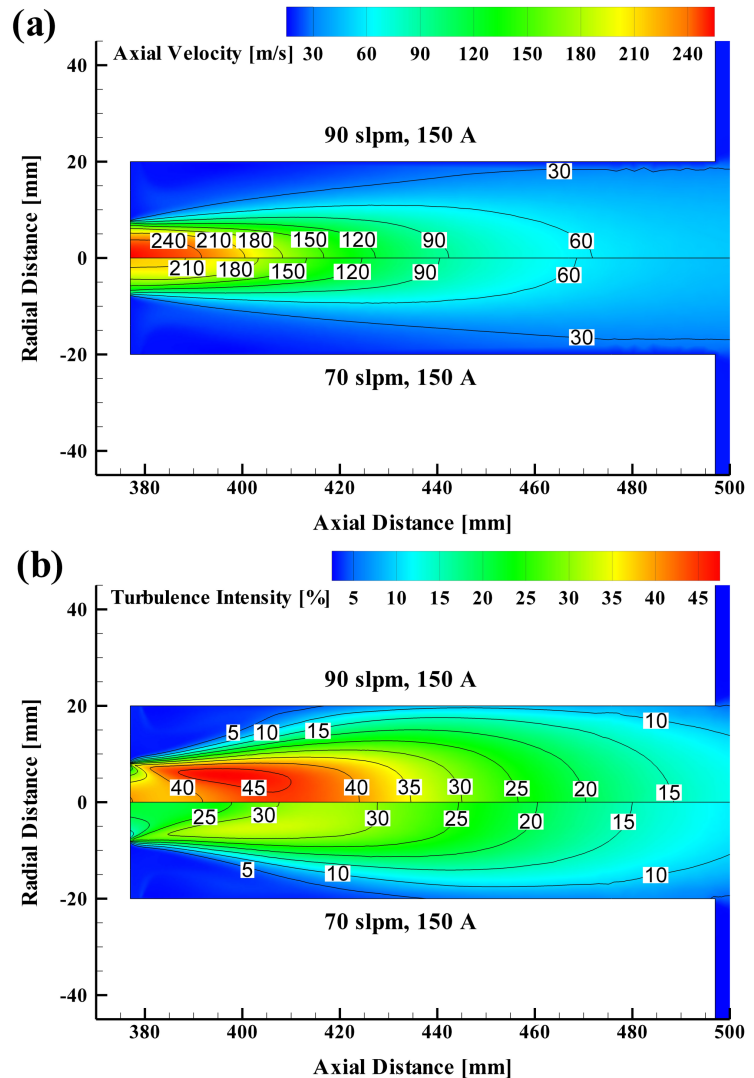

Fig. 7. Contour plots of (a) the velocity and (b) the turbulence intensity of the thermal plasma jet inside the reactor region for flow rates of 70 (below) and 90 (above) slpm at the same arc current of $150 \mathrm{~A}$.

industrial application of thermal plasma pyrolysis to the PFC abatement process due to its low operating costs for electric power and working gas.

\section{ACKNOWLEDGMENTS}

This work was supported by the Ministry of Knowledge Economy through the Regional Innovation Center for Environmental Technology of Thermal Plasma (ETTP) at Inha University.

\section{REFERENCES}

[1] A. R, Ravishankara, S. Solomon, A. A. Turnipseed and R. F. Warren, Sci. 259, 194 (1993).

[2] H. Chae and H. H. Sawin, J. Korean Phys. Soc. 51, 978 (2007).

[3] J. V. Gompel and T. Walling, Semicond. Int. 20, 95 (1997).

[4] D. R. Burgess, Jr., M. R. Zachariah, W. Tsang and P. R. Westmoreland, Prog. Energy Combust. Sci. 21, 453 (1996). 
[5] Y. Kim, K. T. Kim, M. S. Cha, Y. H. Song and S. J. Kim, IEEE Trans. Plasma Sci. 33, 1041 (2005).

[6] S. J. Yu and M. B. Jang, Plasma Chem. Plasma Proc. 21, 311 (2001).

[7] B. A. Wofford, M. W. Jackson, C. Hartz and J. W. Bevan, Env. Sci. Tech. 33, 1892 (1999).

[8] T. Kuroki, J. Mine, S. Odahara, M. Okubo, T. Yamamoto and N. Saeki, IEEE Trans. Ind. Appl. 41, 221 (2005).

[9] M. B. Jang and J. S. Chang, Ind. Eng. Chem. Res. 45, 4101 (2006).

[10] C. L. Hartz, J. W. Ban, M. W. Jackson and B. A. Wofford, Env. Sci. Tech. 32, 682 (1998).

[11] J. W. Sun and D. W. Park, Kor. J. Chem. Eng. 30, 476 (2003).

[12] S. Choi, H. S. Lee, C. H. Lee, J. S. Nam and S. H. Hong, 18th Int. Symp. Plasma Chem. (Kyoto, 2007).
[13] M. Hur, K. S. Kim and S. H. Hong, Plasma Sour. Sci. Tech. 12, 255 (2003).

[14] S. Choi, T. H. Hwang, J. H. Seo, D. U. Kim and S. H. Hong, IEEE Trans. Plasma Sci. 32, 473 (2004).

[15] M. Hur and S. H. Hong, J. Phys. D: Appl. Phys. 35, 1946 (2002).

[16] K. S. Kim, T. H. Hwang, S. Choi, S. H. Hong and H. Shin, J. Korean Phys. Soc. 42, S893 (2003).

[17] K. S. Kim, J. M. Park, S. Choi, J. Kim and S. H. Hong, Phys. Plasmas 15, 023501 (2008).

[18] J. F. Brilhac, B. Pateyron, J. F. Coudert, P. Fauchais and A. Bouvier, Plasma Chem. Plasma Proc. 15, 257 (1995).

[19] H. P. Li, E. Pfender and X. Chen, J. Phys. D: Appl. Phys. 36, 1084 (2003).

[20] E. Pfender, Thin Solid Films 238, 228 (1994). 